\title{
EL USO DE MECANISMOS ALTERNATIVOS DE SOLUCIÓN DE CONTROVERSIAS EN MATERIA ADMINISTRATIVA
}

\section{The Use of Alternative Dispute Resolution in Administrative Matters}

\begin{abstract}
Es inevitable que haya conflictos. No desaparecerán, ni pueden ser ignorados. Para bien o para mal, tendremos que enfrentarnos toda la vida con intereses en conflicto. ${ }^{1}$
\end{abstract}

Tobías GARCÍA TOVAR²

Sumario:

I. La innegabilidad de la existencia del conflicto. II. La permisibilidad jurídica del uso de mecanismos alternativos de solución de controversias en materia administrativa. IIII.- Diversos mecanismos alternativos de solución de controversias reconocidos por la legislación guanajuatense. IV. A manera de conclusión. V. Fuentes consultadas.

Resumen: El artículo plantea la factibilidad de utilizar mecanismos alternativos a la decisión jurisdiccional para resolver las controversias que se presentan en el ámbito administrativo en el estado de Guanajuato; señala diversos ordenamientos que ya los contemplan y destaca aspectos valiosos que tornan recomendable su aplicación.

Palabras Clave: Mecanismos, Alternativo, Controversia, Administrativo, Ley, Procedimiento, Negociación, Mediación, Conciliación, Arbitraje.

Abstract: The article raises the feasibility of using alternative mechanisms to the judicial decision to resolve disputes that arise in the administrative field in the state of Guanajuato; notes that various systems and contemplate and highlights valuable aspects that make recommended its implementation.

Keywords: mechanisms, Alternative, Dispute, Administrative, Law, Procedure, Negotiation, Mediation, Conciliation, Arbitration.

\section{LA INNEGABILIDAD DE LA EXISTENCIA DEL CONFLICTO}

Desde la aparición de los seres humanos sobre la faz de la tierra y su interacción cotidiana, surgieron los conflictos. El libre albedrío y la capacidad de representarse e interpretar la rea-

\footnotetext{
${ }^{1}$ FISHER, Roger, et al., Más allá de Machiavello. Herramientas para afrontar conflictos, traducción Gabriel Zadunaisky, Granica, Buenos Aires, 1999, p.195.

${ }^{2}$ Profesor del Departamento de Derecho de la División de Derecho, Política y Gobierno de la Universidad de Guanajuato.
} 
lidad desde perspectivas individuales o subjetivas provocó la diversidad y esta la existencia de propósitos, intereses, objetivos, necesidades, emociones y sentimientos que no necesariamente eran coincidentes, más bien, en múltiples casos, divergentes y hasta opuestos.

La disputa por la comida, las luchas para demostrar quién tenía más fuerza y por tanto el poder de decidir; la apropiación de espacios para el cultivo; la reclamación de una mujer para procrear o hijos para poder formar una familia, clan o tribu, produjeron incompatibilidades. La búsqueda de dominio sobre personas y territorio ha sido una constante en el devenir histórico.

El conflicto es inherente a la naturaleza humana y es prácticamente imposible erradicarlo. Es muy ilustrativa la metáfora de Sastre Peláez: "El conflicto es, junto con el oxígeno, el nitrógeno y el hidrógeno, uno de los elementos naturales más abundantes." 3 Y resulta impactante la afirmación del filósofo Stuart Hampshire: "No somos obras maestras de nuestras vidas y las vidas de las comunidades no son clases maestras. Buscamos alguna relajación de la tensión, pero, hasta la muerte, no esperamos la desaparición completa del conflicto y la tensión, ni en el alma ni en la sociedad. ${ }^{4}$

Durante mucho tiempo prevaleció la idea de que el conflicto era pernicioso y hasta nefando, no en vano el Diccionario de la Real Academia Española lo define como combate, lucha, pelea; enfrentamiento armado; apuro, situación desgraciada y de difícil salida; problema, cuestión, materia de discusión. ${ }^{5}$

En realidad, pese a que existen visiones negativas, las disputas suelen generar cambios en la realidad que mejoran relaciones interpersonales, comunitarias o internacionales.

Sin duda la existencia de una sociedad plana, quieta, sin sobresaltos, es difícil de imaginar, lo importante es aceptar la existencia de diferencias y establecer los mejores mecanismos o procedimientos que lleven a encontrar soluciones pacíficas y consensuadas que dejen satisfechos a los sujetos conflictuados. Lo importante es generar confianza en la sociedad en la solución obtenida, sea resultado de la voluntad de las partes o de la imposición de un tercero. En todo caso, es fundamental la existencia de ciertos principios rectores que contribuyan a incrementar esa confianza y, sin duda es relevante el de la imparcialidad, al que Hampshire le atribuye un valor esencial, pues bien dice "Existe un principio moral primordial que cualquier ciudadano tiene buenas razones para aceptar y respetar en la práctica: es el principio de la imparcialidad institucionalizada en los procedimientos para resolver ( ) conflictos.” ${ }^{\prime 6}$

Durante siglos las escuelas y facultades de Derecho han enseñado a los abogados la cultura del litigio, de ganar con la ley en la mano y su interpretación, todo tipo de asunto que se someten a su defensa, incluso, no puede negarse, con el uso de falacias, artilugios y martingalas. Un juicio imparcial admite fiabilidad, un mecanismo en el que intervenga un tercero que ayude a la construcción de acuerdos y no favorezca ni afecte indebidamente a ninguna de las partes, crea en éstas mayor satisfacción y fortalece la convivencia racional y armónica, he ahí el gran valor de la imparcialidad.

\footnotetext{
${ }^{3}$ SASTRE PELÁEZ, Antonio, ¡A mediar tocan! Una fábula sobre la mediación y resolución de conflictos, Gedisa, $1^{\text {a }}$ ed., Barcelona, 2008, p. 217.

${ }^{4}$ HAMPSHIRE, Stuart, La Justicia es Conflicto, Traducción de Alfonso Colodrón Gómez, Siglo XXI de España Editores, Madrid, 2002, p. 33.

${ }^{5}$ Véase: http://lema.rae.es/drae/?val=conflicto. Consultada el 4 de mayo de 2015 a las 21:25 horas.

${ }^{6}$ Ibidem, p. 73.
} 
II. LA PERMISIBILIDAD JURÍDICA DEL USO DE MECANISMOS ALTERNATIVOS DE SOLUCIÓN DE CONTROVERSIAS EN MATERIA ADMINISTRATIVA.

Es inobjetable la presencia del conflicto en las relaciones humanas, ante esa realidad, los ordenamientos jurídicos y las sociedades han establecido históricamente distintas vías para encontrar soluciones, bien bajo la sombra de la coerción, o bien privilegiando el diálogo y el entendimiento. El juicio cobró carta de naturalización y se asumió como el instrumento más socorrido, aun cuando existen antecedentes que dan cuenta de otros métodos que de pronto parecieron redescubrirse y hoy se alientan como si fuera un descubrimiento reciente y se incluyen expresamente en las normas.

La Constitución Política de los Estados Unidos Mexicanos, en el párrafo cuarto el artículo 17, establece un mandato a cargo del legislador para que se regulen métodos diversos al juicio para solucionar conflictos. El texto reza literalmente: "Las leyes preverán mecanismos alternativos de solución de controversias. En la materia penal regularán su aplicación, asegurarán la reparación del daño y establecerán los casos en los que se requerirá supervisión judicial."(El resaltado es propio)

Con independencia de los motivos aducidos cuando se reformó esta disposición jurídica, lo importante es que se positivizan los mecanismos alternativos para resolver disputas, en cualquier materia, dentro de las cuales se encuentra la administrativa.

La solución de los diferendos administrativos en la tradicional modalidad heterocompositiva de imposición de la decisión por un tercero dotado de imperium, está reglada en el estado de Guanajuato, en la Ley Orgánica del Tribunal de lo Contencioso Administrativo, que dispone en su artículo 3 la competencia del Tribunal de lo Contencioso Administrativo para resolver los conflictos que se generen entre la Administración Pública estatal y los particulares. ${ }^{7}$ Aunque también posee competencia en asuntos municipales, concretamente tratándose de actos y resoluciones jurídico-administrativos dictadas, ordenadas, ejecutadas

\footnotetext{
${ }^{7}$ El artículo 3 dispone que "El Tribunal tiene a su cargo, dirimir las controversias de carácter administrativo y fiscal que se susciten entre la Administración Pública del Estado y los particulares, así como conocer de los actos y resoluciones administrativas dictadas por los Ayuntamientos."
} 
o que traten de ejecutar los ayuntamientos en agravio de los particulares, ${ }^{8} \mathrm{o}$ incluso de actos emitidos por los presidentes municipales, dependencias o entidades locales. ${ }^{9}$

También los juzgados administrativos municipales tienen competencia para resolver los conflictos de giro administrativo que emerjan de las relaciones entre las administraciones locales y los particulares. ${ }^{10}$

Y la pregunta es, ¿pueden utilizarse mecanismos alternativos al juicio?, la respuesta está dada en la legislación, pero sus alcances son limitados. En primer lugar es conveniente averiguar si se reconocen en algunas normas estatales o es una materia ajena o proscrita.

El Código de Procedimiento y Justicia Administrativa para el Estado y los Municipios de Guanajuato, reconoce que el procedimiento administrativo puede terminar por "Convenio entre los particulares y las autoridades administrativas, cuyo cumplimiento podrá ser demandado ante el Tribunal o los Juzgados" y agrega que "Las autoridades administrativas podrán celebrar con los particulares acuerdos o convenios de carácter conciliatorio que pongan fin a los asuntos, siempre que no sean contrarios a las disposiciones legales aplicables ni afecten derechos de terceros".

Estas disposiciones son de capital importancia en virtud de que abren una puerta importante para identificar la posibilidad de hacer uso de mecanismos alternos de solución de los conflictos que aparecen entre las administraciones públicas estatal y locales con los particulares, sean personas naturales o colectivas.

Es cierto que no todo procedimiento de índole administrativa tiene necesariamente que identificarse con una controversia. Más aún, es conveniente recordar que el procedimiento administrativo tiene varias funciones, por una parte es constitutivo, es decir, se significa como el conjunto articulado de actos y formalidades que se suceden en el tiempo para la producción del acto administrativo; por otra parte, es la sucesión de formalidades y actos que se encaminan a impugnar un acto o resolución de la administración pública, en sede

\footnotetext{
${ }^{8}$ Así se lee en el artículo 20, fracción VIII de la mencionada Ley.

9 Artículo 243 de la Ley Orgánica Municipal para el Estado de Guanajuato: "Los actos y resoluciones administrativas dictadas por el Ayuntamiento, podrán ser impugnados ante el Tribunal de lo Contencioso Administrativo cuando afecten intereses de los particulares.

Los actos y resoluciones administrativas dictadas por el presidente municipal y por las dependencias y entidades de la administración pública municipal podrán ser impugnados optativamente ante los juzgados administrativos municipales o ante el Tribunal de lo Contencioso Administrativo, cuando afecten intereses de los particulares. Ejercida la acción ante cualquiera de ellos, no se podrá impugnar ante el otro el mismo acto.

Las resoluciones de los Juzgados Administrativos Municipales que pongan fin al proceso administrativo podrán ser impugnados por las partes, mediante el recurso de revisión ante las Salas del Tribunal de lo Contencioso Administrativo."

${ }^{10}$ Idem, artículo 244 "Los juzgados administrativos municipales son depositarios de la función jurisdiccional del Municipio, están dotados de plena autonomía para dictar sus fallos, así como de plena jurisdicción e imperio para hacer cumplir sus resoluciones, siendo órganos de control de legalidad que tienen a su cargo dirimir las controversias administrativas que se susciten entre la administración pública municipal y los gobernados. Su relación jurídica se establecerá directamente con el Ayuntamiento. El Presidente Municipal sólo podrá ejecutar sobre estos órganos jurisdiccionales municipales, los acuerdos e instrucciones que apruebe el Ayuntamiento.

La actuación de los Juzgados Administrativos Municipales se sujetará a los principios de legalidad, publicidad, audiencia e igualdad. “

${ }^{11}$ Véanse artículos 198 fracción III y 200 del Código de Procedimiento y Justicia Administrativa para el Estado y los Municipios de Guanajuato.
} 
interna; ${ }^{12} y$, en una tercera acepción, se concibe como esa misma sucesión de formalidades y actos que se orientan a obtener la ejecución de un acto o resolución administrativa.

El propio Dromi alude a etapas procedimentales y sostiene que existe "una primera, de formación de la voluntad administrativa, de origen unilateral o bilateral de efectos individuales o generales; y otra de fiscalización, control e impugnación, que comienza cuando la primera concluye... Comprende tanto el procedimiento que regula la formulación del acto (constitutivo) como su cuestionamiento y fiscalización".13

Nuestro legislación recoge la vertiente constitutiva del procedimiento, pero también logra abrazar la impugnación y la ejecución, pues existen diversos ordenamientos que señalan la secuencia creativa del acto, medios de impugnación y el camino a seguir para ejecutarlo hacerlo efectivo.

Por lo que se refiere a la formación del acto, baste consultar lo dispuesto por el artículo 137, fracción VIII del citado Código de Procedimiento y Justicia Administrativa para el Estado y los Municipios de Guanajuato, que reclama como un elemento de validez del acto administrativo: "Ser expedido de conformidad con las formalidades del procedimiento administrativo que establecen los ordenamientos jurídicos aplicables y en su defecto, por lo dispuesto en este Código", lo cual zanja cualquier debate.

En torno a la existencia de procedimiento administrativo impugnativo, es suficiente acudir a la regulación que hace el propio código del recurso de Inconformidad, resultando ilustrativa la denominación del Título Sexto, "Defensa de los Particulares". El recurso tiene por objeto confirmar, modificar, revocar u obtener la nulidad del acto administrativo recurrido, como se lee en el numeral 227. El trámite es consultable en los arábigos 228 a 248.

Y con relación al procedimiento de ejecución por supuesto que no habría que acudir a todo el ordenamiento administrativo, sin embargo, es suficiente, para los efectos que se persiguen en este artículo, demostrar que el cuerpo normativo citado contiene normas procedimentales útiles para la ejecución del acto administrativo. Así se desprende de los artículos 141 y 142, que aluden a la exigibilidad del acto, y de manera preponderante lo previsto en el 148, que ninguna duda deja, al prescribir que "Las autoridades administrativas podrán proceder, previo apercibimiento, a la ejecución forzosa de los actos administrativos, salvo en los supuestos en que se suspenda la ejecución de acuerdo con las leyes o éstas exijan la intervención de los tribunales." Es decir, la ejecución del acto, se da siguiendo un procedimiento administrativo y si alguna duda quedare sobre cuál es ese procedimiento, la respuesta es simple: hay que acudir a lo que resulta aplicable del propio Código.

Esta aparente digresión cobra sentido por dos razones: la primera para afianzar la noción de que la utilización de mecanismos alternos de solución de controversias suscitadas por las relaciones entre las administraciones públicas subnacional y locales, es constitucional y legal; la segunda, para identificar el momento en que pueden celebrarse los convenios y la relación que estos guardan con aquellos.

Hasta aquí puede asumirse indubitable que los mecanismos diferentes al proceso para solucionar diferendos, son aplicables en el ámbito administrativo porque la Constitución Política de los Estados Unidos Mexicanos lo afirma en forma expresa y contundente, y del texto normativo se sigue un amplio espectro para que los legisladores de las entidades fede-

\footnotetext{
${ }^{12}$ DROMI, Roberto, El Procedimiento Administrativo, Ciudad Argentina Editorial de Ciencia y Cultura, Buenos Aires, 1999, pp.111 y 112.

${ }^{13}$ DROMI, Roberto, Derecho Administrativo, Novena edición, Ciudad Argentina Editorial de Ciencia y Cultura, Buenos Aires, 2001, Pp. 1016 y 1017.
} 
rativas puedan hacerlo en cualquier materia, salvo en el ámbito penal, puesto que el artículo 73, fracción XXI, inciso c) de la norma suprema, la reserva al Congreso de la Unión.

Y aquí vale la pena hacer un paréntesis para señalar enfáticamente que el criterio orientador de la Constitución federal, es extensivo, pueden acogerse cualesquiera de los métodos alternativos conocidos, o bien los que creativamente puedan diseñar los órganos legislativos. En esta materia lo que prepondera es la imaginación y la búsqueda de procedimientos ágiles, eficaces, económicos y satisfactorios. Lo que debe quedar claro es la importancia de que los poderes legisladores no se autolimiten como se desprende de lo previsto en la Constitución Política para el Estado de Guanajuato que lamentablemente recorta a la mediación y la conciliación, los mecanismos alternativos de solución de conflictos. ${ }^{14}$ Lo anterior no es óbice alguno para que las leyes secundarias que los contemplen sean perfectamente constitucionales.

Es conveniente en términos diacrónicos o de oportunidad, identificar en qué momento puede aplicarse uno de estos procedimientos alternativos a la solución de un conflicto en el ámbito administrativo. Regularmente se ha visto el tema vinculado con el proceso, y así, se plantea que el método o procedimiento puede emplearse pre-procesalmente, es decir, antes de que inicie la disputa ante los tribunales; intra-procesalmente, cuando el juicio se encuentra en trámite; post-procesalmente, una vez terminado el litigio judicial, o bien metaprocesalmente, es decir, al margen de toda actividad jurisdiccional.

En una primera postura, sería dable afirmar la posibilidad de acudir a estas formas de resolver conflictos en cualquier momento, sin embargo, se requiere tomar en cuenta las particularidades de la materia administrativa.

Aquí es importante determinar en qué momento surge la controversia y es necesario recordar algunos concepto de conflicto. Barbara A. Budjac sostiene que el conflicto "Existe donde y cuando sea que haya una incompatibilidad de cogniciones o emociones en los individuos o entre grupos de individuos... implica como necesaria una interdependencia percibida o real." ${ }^{15}$ De esta idea podemos extraer la exigencia de que el conflicto solamente puede existir cuando hay una interdependencia entre sujetos y una percepción de incompatibilidad.

Sin perjuicio de profundizar, adelantemos desde esta noción que un conflicto administrativo está presente cuando un particular y un órgano administrativo tienen una relación de la cual surge la interdependencia y entre ellos aparece una percepción de incompatibilidad. Y en qué momento surge esta situación de diferencia, pues en cualquiera en que se presenta el contacto entre uno y otro; los ejemplos serían inagotables: desde la desatención a un particular por parte de un servidor público frente a la mera petición de información hasta la

\footnotetext{
${ }^{14}$ Artículo 2, párrafos quinto, sexto y séptimo: "La Ley establecerá y regulará la mediación y la conciliación como medios alternativos para la resolución de las controversias entre las partes interesadas, respecto a derechos de los cuales tengan libre disposición.

La mediación y la conciliación se regirán bajo los principios de equidad, imparcialidad, rapidez, profesionalismo y confidencialidad. El Poder Judicial contará con un órgano de mediación y conciliación el cual actuará en forma gratuita a petición de parte interesada. Dicho órgano tendrá la organización, atribuciones y funcionamiento que prevea la Ley.

La Ley regulará la aplicación de mecanismos alternativos de solución de controversias en la materia penal, en los que se asegure la reparación del daño y se establezcan los casos en los que se requerirá supervisión judicial." Por cierto, para cumplir con lo previsto en la Constitución federal, se avizora una necesaria modificación a estas disposiciones normativas.

${ }^{15}$ BUDJAC CORVETTE, Barbara A., Técnicas de negociación y resolución de conflictos, $1^{\mathrm{a}}$ ed., Pearson Educación, México, 2011, p. 34.
} 
revocación de una concesión, pasando por la negativa a otorgar un permiso, la imposición de una clausura, el requerimiento para retirar anuncios, la detención de un transeúnte porque se le impide el paso a un determinado lugar; en fin, puede aseverarse que las relaciones particulares-administraciones son una auténtica fuente permanente de conflictos.

Nuestra legislación no identifica lo que debe entenderse por conflicto o controversia, pero alude al término en diferentes normas, o bien, lo identifica con litigio. El Código de Procedimiento y Justicia Administrativa del Estado hace mención a esta voz sólo cuando se regula la suspensión, pero no lo define, no obstante, es obvio que este ordenamiento se inspira en el Código de Procedimientos Civiles para el Estado de Guanajuato, cuyo artículo 71 reza: "Dos partes se encuentran en litigio cuando una pretende que el Derecho apoya en su favor un interés en conflicto con el interés de la otra y ésta se opone a la pretensión, o, aun no oponiéndose, no cumple con la obligación que se le reclama." Sin duda es una concepción que reduce los conflictos a aquellos de naturaleza jurídica y que los somete al método tradicional de adjudicación para su solución.

Con independencia de la naturaleza específica del conflicto que surge de las relaciones entre las administraciones y los particulares, lo importante es encontrar su resolución sin necesidad de judicializarse. En la realidad hay múltiples entuertos que se resuelven por diversas vías.

III. DIVERSOS MECANISMOS ALTERNATIVOS DE SOLUCIÓN DE CONTROVERSIAS RECONOCIDOS POR LA LEGISLACIÓN GUANAJUATENSE

Son diversos los métodos alternos reconocidos de maneta expresa por nuestro Derecho, y más que válidamente podrían ser empleado por las autoridades y los ciudadanos. Como se mencionaba supra, el artículo 200 del Código de Procedimiento y Justicia Administrativa para el Estado y los Municipios de Guanajuato, dispone que "Las autoridades administrativas podrán celebrar con los particulares acuerdos o convenios de carácter conciliatorio que pongan fin a los asuntos, siempre que no sean contrarios a las disposiciones legales aplicables ni afecten derechos de terceros."

$\mathrm{El}$ análisis de este enunciado normativo abre la puerta a una figura alterna al juicio para resolver un conflicto, que es la conciliación e implícitamente, en mi concepto, a la negociación y a la mediación. Esta afirmación se corrobora al confrontarla contra lo recogido en la Ley de Justicia Alternativa del Estado de Guanajuato, que define a la mediación como el trámite a través del cual uno o más mediadores intervienen para facilitar la comunicación directa, respetuosa y confidencial entre las personas en controversia, con el propósito de que éstas lleguen por sí a un acuerdo voluntario que le ponga fin, y precisa que la conciliación ocurre cuando los interesados no llegan por sí mismos a un acuerdo que resuelva su controversia, caso en el cual, el tercero neutral les presentará alternativas de solución viables, que armonicen sus intereses, explorando formas de arreglo y asistiéndoles para elaborar el documento idóneo que dé solución adecuada a la controversia. ${ }^{16}$

La diferencia esencial, que no es pacífica, entre la mediación y la conciliación, radica en la intensidad y proactividad de la intervención del tercero neutral y en la capacidad de los disputantes para llegar a un acuerdo por sí o inducidos por aquél. En otras palabras, la mediación supone que el conflictólogo o facilitador, propicie el diálogo, aliente a las partes a que encuentre por sí mismos la solución a su conflicto, el cual, una vez obtenido, será producto

\footnotetext{
$\overline{{ }^{16} \text { Véase el artículo } 7}$ de la Ley de Justicia Alternativa del Estado de Guanajuato.
} 
de su voluntad; por su parte, en la conciliación, su papel es más activo y puede presentar a los interesados alternativas de solución para que estos los ponderen y las acojan, también voluntariamente. En uno y en otro caso se soluciona el conflicto con un convenio.

Si la ley alude a "acuerdo o convenios de carácter conciliatorio" evidentemente está permitiendo que la administración y el ciudadano puedan dialogar pacífica, informal y voluntariamente para poder zanjar la diferencia. Para llegar a un acuerdo pueden negociar, mediar o conciliar la disputa.

Es obvio que se puede negociar, si entendemos con Highton y Álvarez, que la negociación "Es un proceso voluntario, predominantemente informal, no estructurado, que las partes utilizan para llegar a un acuerdo mutuamente aceptable". ${ }^{17}$ Es evidente desde esta perspectiva, que se puede llegar al acuerdo o convenio conciliatorio mediante esta figura en la cual la sola presencia de la administración estatal o local y el particular o interesado, puede generarlo y dejarlos satisfechos.

Siguiendo a las mismas actoras, es posible que en materia administrativa se concilie, pues como bien dicen, "conciliar supone avenimiento entre intereses contrapuestos; es armonía establecida entre dos o más personas con posiciones disidentes", además, asumen que la conciliación es un mecanismo para resolver autocompositivamente los conflictos y puede reflejarse en el desistimiento, allanamiento o transacción. ${ }^{18}$ Ellas mismas definen a la mediación como un "procedimiento no adversarial en el que un tercero neutral, que no tiene poder sobre las partes, ayuda a éstas a que en forma cooperativa encuentren el punto de armonía en el conflicto... En líneas generales, el término se utiliza para describir un procedimiento en el cual un tercero imparcial ayuda a las partes a comunicarse y a realizar elecciones voluntarias e informadas, en un esfuerzo por resolver su conflicto" ${ }^{19}$

En este contexto, es perfectamente posible emplear en Guanajuato la negociación, la mediación y la conciliación en el ámbito administrativo, con la sola aplicación de la legislación aludida.

Para robustecer la clara vocación del legislador de adoptar mecanismos alternativos de solución de conflictos, es conveniente aludir a otras normas positivas en las que se encuentran recogidos y que no han sido debidamente aprovechadas.

El 27 de junio del 2014 se publicó en el Periódico Oficial del Gobierno del Estado de Guanajuato, la Ley para Prevenir, Atender y Erradicar la Discriminación en el Estado de Guanajuato, en vigor a partir del día siguiente.

Este ordenamiento prohíbe "toda conducta discriminatoria que tenga por objeto o efecto impedir, anular o menoscabar el reconocimiento o ejercicio de los derechos y la igualdad real de oportunidades", ${ }^{20}$ y crea un Consejo, entre cuyas atribuciones se encuentran las de "Conocer y recibir las quejas de las presuntas conductas y prácticas discriminatorias de par-

\footnotetext{
${ }^{17}$ HIGHTON, Elena I. y ÁLVAREZ, Gladys S. Mediación para Resolver Conflictos, Primera reimpresión de la segunda edición, Ad-Hoc, Buenos Aires, 1998, P. 119.

${ }^{18}$ Ibidem, pp. 101 a 104.

19 Ibidem, p. 195.

${ }^{20}$ Véase el artículo $8^{\circ}$ de la citada ley. 
ticulares y servidores públicos estatales y municipales que le sean presentadas"21 e "Impulsar los convenios conciliatorios y dictar acuerdo de conclusión del expediente de queja".22

Se crea un procedimiento para tramitar las quejas y dentro de mismo una etapa conciliatoria, en la que el Consejo procura avenir a las partes, a partir de las soluciones que "se propongan", lo cual debe entenderse como emergidas de las parte quejosa y la generadora de la conducta discriminatoria, e incluso del facilitador o conciliador. Ciertamente, la Ley excluye de la conciliación los casos graves y los que impliquen un riesgo inminente de nueva afectación a la persona quejosa.

Quienes pueden fungir como conciliadores son el personal del Consejo, o bien, los mediadores del Centro Estatal de Justicia Alternativa del Poder Judicial del Estado (la ley equivocadamente adscribe ese Centro, al Supremo Tribunal de Justicia del Estado), y es muy alentador que permita que las audiencias sean presenciales, "por escrito, medios electrónicos u otros igualmente aceptables", es decir, se acepta la conciliación on line. Si se celebra convenio conciliatorio, este tendrá autoridad de cosa juzgada y, por tanto, traerá aparejada ejecución. ${ }^{23}$

Otro supuesto reciente de asunción de mecanismos alternativos de solución de conflictos administrativos, se desprende de la indebidamente denominada Ley de Contrataciones Públicas para el Estado de Guanajuato, ${ }^{24}$ y digo indebidamente, porque en la legislación estatal existe también una ley reguladora de la obra pública y servicios relacionados con ella, que norma el contrato administrativo en que debe formalizarse. El objeto de aquella ley, es regular, controlar y vigilar actos y contratos que se celebren en materia de adquisiciones, enajenaciones y arrendamientos de bienes muebles e inmuebles y de prestación de servicios.

El artículo 19 establece que los conflictos que se generen "podrán ser resueltos de común acuerdo por las partes en conflicto; por arbitraje o por los órganos de control, en la forma prevista por esta ley, o en su defecto por el Tribunal de lo Contencioso Administrativo del Estado de Guanajuato". Deja a los poderes legislativo y judicial la resolución de los conflictos en los que ellos participen, a los ordenamientos que regulan su actuación de manera específica.

Sin duda esta Ley abre un camino que ya se recorría por la legislación federal, pero que en Guanajuato era inédito en materia de contratos administrativos, y es la posibilidad de acudir al arbitraje, figura alternativa al juicio o a los recursos administrativos, que es propicia y recomendable para resolver diferendos con rapidez para lograr que cuestiones tan importantes como las obras públicas, se culminen para satisfacer las necesidades generales que justifican su realización.

En una valiosa síntesis, Francisco González de Cossío describe el sistema internacional de fuentes del arbitraje, ${ }^{25}$ destacando la relevancia de la Convención Sobre el Reconocimiento y Ejecución de Sentencias Arbitrales Extranjeras de 10 de julio de 1958, mejor conocida como la "Convención de Nueva York", ${ }^{26}$ a la cual se adhirió México desde 1971.

¿Y qué es al arbitraje? El propio González de Cossío cita la a Charles Jarroson, quien de manera muy clara y comprensible lo define como "una institución por la cual un tercero

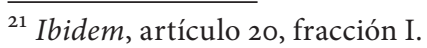

${ }^{22}$ Idem, fracción XV.

${ }^{23}$ La etapa conciliatoria está regulada en los artículos 48 a 56 de la Ley.

${ }^{24}$ Publicada en el Periódico Oficial del Gobierno del Estado de Guanajuato del 26 de diciembre de 2014 y en vigor a partir del día 1 de febrero del año 2015.

${ }^{25}$ GONZÁlEZ DE COSSÍO, Francisco. Arbitraje, Tercera Edición, Porrúa, México, 2011, pp. 3 y ss.

${ }^{26}$ Véase: http://www.uncitral.org/uncitral/es/uncitral_texts/arbitration/NYConvention.html. Consultada el 14 de abril de 2015 a las 21:25 horas.
} 
resuelve una diferencia que divide a dos o más partes en ejercicio de la misión jurisdiccional que la ha sido confiada por ellos". ${ }^{27}$ El Código de Comercio, por su parte, se reduce a señalar en su artículo 1416, fracción II, que se entenderá por "Arbitraje, cualquier procedimiento arbitral de carácter comercial, con independencia de que sea o no una institución arbitral permanente ante la que se lleve a cabo" (las cursivas son propias); así de simple, lo cual no supone más que la evidente intención de reconocerlo como un procedimiento que no debe tener mayores complicaciones.

La obra del autor que se cita, que por cierto es un árbitro mexicano con experiencia internacional, resulta profundamente aleccionadora y ninguna duda deja de la utilidad y conveniencia de hacer uso del procedimiento arbitral para resolver una amplia gama de conflictos, que de pronto parecerían inverosímiles para los administrativistas, pero baste mencionar el caso que el mismo tratadista ilustra en materia de obra, al referirse a las controversias derivadas de la construcción del Túnel, entre Francia y el Reino Unido, que se ventilaron mediante el arbitraje ante la Corte Permanente de Arbitraje de La Haya. ${ }^{28}$

Aparentemente la inclusión de este mecanismo en la legislación local, abre un baúl de interrogantes de difícil respuesta; en realidad eso es falso. Por ejemplo, se comenta que es una figura extraña al derecho Administrativo, a lo cual habrá que contestar de manera muy sencilla que ninguna figura o institución jurídicamente regulada es ajena a un sistema normativo. Se alega que no existen árbitros, lo que ningún problema representa pues lo importante es que las partes se pongan de acuerdo en la designación de quienes fungirán con ese carácter para dirimir una controversia, y en el peor de los casos, se puede acudir a los que forman parte de diferentes organizaciones, entre las cuales destaca el Centro de Arbitraje de México, que tiene sus propias reglas para tramitar un procedimiento arbitral. ${ }^{29}$

El propósito de este artículo no es explayarse en alguna figura en específico, por lo que no se profundizará en el desarrollo de los beneficios del arbitraje. La intención es mostrar el reconocimiento normativo de acudir a mecanismos o procedimiento alternativos al juicio, para disolver conflictos en materia administrativa, con especial énfasis en lo que ocurre en el estado de Guanajuato.

No es un tema extraño el uso del arbitraje para resolver conflictos en materia de contratos administrativos, en España, por ejemplo, el artículo 50 del Real Decreto Legislativo 3/2011, de 14 de noviembre, por el que se aprueba el texto refundido de la Ley de Contratos del Sector Público señala que "Los entes, organismos y entidades del sector público que no tengan el carácter de Administraciones Públicas podrán remitir a un arbitraje, conforme a las disposiciones de la Ley 60/2003, de 23 de diciembre 2 de Arbitraje, la solución de las diferencias que puedan surgir sobre los efectos, cumplimiento y extinción de los contratos que celebren. ${ }^{30}$

Por otra parte, el artículo 93 fracción I último párrafo de la Ley de Obra Pública y Servicios Relacionados con la Misma para el Estado y los Municipios de Guanajuato, dispone que "La contratante podrá suspender el trámite del procedimiento de rescisión, cuando se

\footnotetext{
27 Op.cit., p.45

${ }^{28}$ Ibidem, p. 28.

${ }^{29}$ Véase http://www.camex.com.mx/images/pdf/reglas-vigentes-espanol.pdf. Consultada el 14 de abril de 2015 a las 22:00 horas.

30 Véase: http://noticias.juridicas.com/base_datos/Admin/rdleg3-2011.html\#lit1c6. Consultada el 16 de abril de 2015 a las 09:40 horas.
} 
hubiere iniciado una conciliación respecto del contrato materia de la rescisión". He ahí otro mecanismo alternativo aplicable a asuntos administrativos envueltos en un diferendo.

En materia de responsabilidad patrimonial del estado, la ley reguladora en Guanajuato, ${ }^{31}$ señala en su artículo 46 como formas de terminación del procedimiento de reclamación del pago del daño causado por entes públicos estatales o municipales, el convenio o transacción de las partes, mediante la fijación y el pago de la indemnización que las mismas acuerden, en cualquier momento del procedimiento; el desistimiento y el cumplimiento voluntario por parte del sujeto obligado, antes de la resolución definitiva.

Es incontestable que el convenio procede del uso de un mecanismo alternativo de solución de la controversia, e incluso, el propio desistimiento y el cumplimiento voluntario, perfectamente podrían tener el mismo origen.

Como se ha visto, a tono con lo previsto por la Constitución Política de los Estados Unidos Mexicanos, ha operado una vis expansiva de los procedimientos que solucionan los conflictos como alternativa al juicio, y cada vez aparecen en más ordenamientos. Lo más reciente que ha ocurrido en el estado de Guanajuato, es la reforma al Código de Procedimiento y Justicia Administrativa para el Estado y los Municipios de Guanajuato, ${ }^{32}$ que, adiciona la fracción $\mathrm{V}$ del artículo 262, cuyo texto reconoce como causa de sobreseimiento del proceso administrativo (el):

"V. Convenio celebrado entre las partes, siempre y cuando no sea contrario a las disposiciones jurídicas normativas ni afecte los derechos de tercero. Los convenios respectivos podrán ser aprobados por el Magistrado de la Sala de conocimiento o por los juzgados administrativos municipales, y producirán todos sus efectos jurídicos inherentes a una sentencia ejecutoria, con autoridad de cosa juzgada.

Cuando el convenio sea obscuro, irregular o incompleto, la autoridad podrá requerir a las partes para que lo aclare, corrija o complete en un término de tres días, apercibiéndolo que, de no hacerlo se tendrá por no presentado."

Además, se incorpora un segundo párrafo al artículo 321, cuyo tenor es: "Se podrá tener por cumplida la sentencia mediante convenio celebrado por las partes, siempre y cuando la forma de cumplimiento no afecte el orden público, ni derechos de terceros, el cual surtirá todos sus efectos legales una vez que sea ratificado por el Tribunal."

Sin pretender realizar un análisis exhaustivo de la reforma ni de las deficiencias de técnica de legislativa que saltan a la vista, sólo destacaré que, aun cuando no se señale expresamente la existencia de un mecanismo alternativo de solución de controversias, es evidente que el convenio procede, al menos, de una negociación, conciliación o mediación a la que han concurrido las partes, y podrá celebrarse, tanto para terminar el proceso que se encuentra

\footnotetext{
${ }^{31}$ Ley de Responsabilidad Patrimonial del Estado y los Municipios de Guanajuato, publicada en el Periódico Oficial del Gobierno del Estado de Guanajuato número 4, Segunda Parte, de fecha 7 de enero de 2005.

${ }^{32}$ Periódico Oficial del Gobierno del Estado de Guanajuato número 78, Tercera Parte, de fecha 15 de mayo del 2015.
} 
en trámite como para el cumplimiento de la sentencia; es decir, puede ser intraprocesal o post procesal.

Caben algunas preguntas que por los alcances de este artículo no se elucidarán ahora, por ejemplo ¿Qué acción asiste a la autoridad o el particular cuando se tiene por cumplida la sentencia por la presencia de un convenio y, sin embargo, el mismo no es satisfecho?

La realidad parece evidenciar que se han venido realizando autocomposiciones en asuntos administrativos que se sustanciaban ante el tribunal estatal especializado en la materia, y derivaban en del desistimiento del particular por la existencia de una previa negociación y celebración de convenios, los cuales, evidentemente no se presentaban ante ese órgano jurisdiccional pues carecía de competencia para sancionarlo y dotarlo de efectos jurídicos, de manera que lo hecho por el legislador es recoger normativamente lo que constituía una práctica para nada inusual. ${ }^{33}$

Más allá de cualquier discusión, lo verdaderamente importante es destacar el reconocimiento normativo que se hace de la diversidad de procedimientos que permiten resolver un conflicto de naturaleza administrativa, para concluir un procedimiento o un proceso. Lo cual no es extraño en el mundo, pues varios países los impulsan o los privilegian para buscar agilidad en la solución de los diferendos en términos amigables, equitativos y desformalizados, como ocurre en el Reino Unido, Francia y Alemania, ${ }^{34}$ entre otros.

En la legislación de diferentes entidades federativas mexicanas también se han venido incluyendo figuras de este tipo. ${ }^{35}$

${ }^{33}$ VALADEZ REYES, Miguel, Mecanismos Alternativos de Solución de Controversias. Visiones y Experiencias, artículo de Lara Martínez Arturo: "Medios alternos de solución de conflictos en materia contenciosa Administrativa", Poder Judicial del Estado de Guanajuato, Escuela de Estudios e Investigación Judicial, Guanajuato, 2014, pp. 351 a 363.

34 Véase MASUCCI, Alfonso. "El Procedimiento de Mediación como Medio Alternativo de Resolución de Litigios en el Derecho Administrativo. Esbozo de las experiencias francesa, alemana e inglesa", Revista de Administración Pública (RAP), número 178, enero-abril de 2009, Madrid, pp. 9 a 35.

${ }^{35}$ El artículo 56, fracción VI de la Ley del Procedimiento Administrativo del Estado de Aguascalientes, establece como una causa de terminación de ese procedimiento: "VI. El convenio de las partes, siempre y cuando no sea contrario al ordenamiento jurídico ni verse sobre materias que no sean susceptibles de transacción y tengan por objeto satisfacer el interés público, con el alcance, efectos y régimen jurídico específico que en cada caso prevea la disposición que lo regula."

Por su parte, el artículo 265 del Código de Procedimientos Administrativos del Estado de México, dispone:" En cualquier momento de la tramitación del proceso administrativo, o en la etapa de cumplimiento de sentencia y ante la Dirección de Mediación y Conciliación, las partes podrán llegar a arreglos conciliatorios que pongan fin al asunto, siempre que no sean contrarios a las disposiciones legales aplicables. Los acuerdos o convenios respectivos aprobados por el magistrado de la sala del conocimiento producirán todos los efectos jurídicos inherentes a una sentencia ejecutoria."

La Ley de Justicia Administrativa para el Estado de Sinaloa señala en su artículo "67 BIS-A. Las partes podrán celebrar convenios para conciliar sus intereses en cualquier etapa del juicio hasta antes de que se dicte sentencia. En tal caso, dichos convenios deberán presentarse para su ratificación y aprobación ante la Sala respectiva para que sean elevados a la categoría de cosa juzgada." Por otro lado, el numeral 67 BIS-B., preceptúa que "En los casos en que exista tercero interesado, la Sala aprobará el convenio únicamente cuando dicho tercero manifiesta su conformidad, suscribiendo el convenio conjuntamente con las partes. Cuando sean varias las autoridades demandadas, será suficiente con que el convenio esté suscrito por la autoridad que generó el acto impugnado, entendiéndose que queda sin materia el juicio."

Véanse también, sólo a manera de ejemplos, los artículos 49, 114 y 133 de la Ley de Justicia Administrativa para el Estado y Municipios de Nuevo León, así como los cardinales $3^{\circ}, 4^{\circ}, 5^{\circ}, 6^{\circ}, 31$ y 32 de la Ley de Métodos Alternos para la Solución de Conflictos del Estado de ese mismo estado; artículos 15 y 22 de la Ley de Justicia Administrativa del Estado de Tabasco; artículos 190 y 192 de la Ley de Equilibrio Ecológico y Protección al Ambiente del Estado de Chihuahua. 


\section{A MANERA DE CONCLUSIÓN}

Los diferendos en materia administrativa pueden ser solucionados a través del uso de mecanismos alternativos al juicio, con notables beneficios para las partes, pues son desformalizados, ágiles, voluntarios, más económicos e incrementan la confianza en los entes públicos. La Constitución Política de los Estados Unidos Mexicanos prevé su uso en todas las materias y por tanto, se incluye la administrativa; en concordancia con ella, la legislación secundaria los ha ido incorporando en diversos cuerpos normativos, aunque no se incluye toda la gama que aparece en el escenario mundial, no obstante, es previsible su mayor promoción y adopción en el corto plazo.

Las instituciones educativas que ofrecen estudios de Derecho, deberían incluir como asignaturas obligatorias, tanto la Teoría y Dinámica del Conflicto como los Mecanismos Alternativos de Solución de Controversias. Es necesario promover una cultura de paz, diálogo, entendimiento y solución cordial de los entuertos, incluyendo los de cariz administrativo; al final, gana el estado, gana la sociedad, gana el mercado y ganan los ciudadanos.

\section{FUENTES}

BIBLIOGRÁFICAS

BUDJAC CORVETTE, Barbara A., Técnicas de negociación y resolución de conflictos, Pearson Educación, Primera Edición, México, 2011.

DROMI ROBERTO, El Procedimiento Administrativo, Ciudad Argentina Editorial de Ciencia y Cultura, Buenos Aires, 1999.

, Derecho Administrativo, Ciudad Argentina Editorial de Ciencia y Cultura, Novena edición, Buenos Aires, 2001.

FISHER, Roger, et. al., Más allá de Machiavello Herramientas para afrontar conflictos, traducción Gabriel Zadunaisky, Granica, Buenos Aires, 1999.

GONZÁlEZ DE COSSÍO, Francisco, Arbitraje, Porrúa, Tercera Edición, México, 2011.

HAMPSHIRE, Stuart, La Justicia es Conflicto, Traducción de Alfonso Colodrón Gómez, Siglo XXI de España Editores, Madrid, 2002.

HIGHTON, Elena I. y ÁLVAREZ, Gladys S., Primera reimpresión de la segunda edición. Ad-Hoc, Buenos Aires, 1998.

MASUCCI, Alfonso, "El Procedimiento de Mediación como Medio Alternativo de Resolución de Litigios en el Derecho Administrativo. Esbozo de las experiencias francesa, alemana e inglesa”, en Revista de Administración Pública (RAP), número 178, eneroabril de 2009, Madrid.

SASTRE PELÁEZ, Antonio, ¡A mediar tocan! Una fábula sobre la mediación y resolución de conflictos, Gedisa Editorial, Barcelona, 2008.

VALADEZ REYES, Miguel (coord.), Mecanismos Alternativos de Solución de Controversias. Visiones y Experiencias, Lara Martínez Arturo, "Medios alternos de solución 
de conflictos en materia contenciosa Administrativa", Poder Judicial del Estado de Guanajuato, Escuela de Estudios e Investigación Judicial, Guanajuato.2014.

\section{LEGISLACIÓN}

Constitución Política de los Estados Unidos Mexicanos.

Constitución Política para el Estado de Guanajuato.

Código de Procedimientos Administrativos del Estado de México.

Código de Procedimientos Civiles para el Estado de Guanajuato, Código de Procedimiento y Justicia Administrativa para el Estado y los Municipios de Guanajuato.

Ley de Contrataciones Públicas para el Estado de Guanajuato.

Ley de Equilibrio Ecológico y Protección al Ambiente del Estado de Chihuahua.

Ley de Justicia Administrativa del Estado de Tabasco.

Ley de Justicia Administrativa para el Estado de Sinaloa.

Ley de Justicia Administrativa para el Estado y Municipios de Nuevo León,

Ley de Justicia Alternativa del Estado de Guanajuato.

Ley de Métodos Alternos para la Solución de Conflictos del Estado de Nuevo León.

Ley de Obra Pública y Servicios Relacionados con la Misma para el Estado y los Municipios de Guanajuato.

Ley de Responsabilidad Patrimonial del Estado y los Municipios de Guanajuato.

Ley del Procedimiento Administrativo del Estado de Aguascalientes.

Ley Orgánica del Tribunal de lo Contencioso Administrativo del Estado de Guanajuato.

Ley Orgánica Municipal para el Estado de Guanajuato.

Ley para Prevenir, Atender y Erradicar la Discriminación en el Estado de Guanajuato

Real Decreto Legislativo 3/2011, de 14 de noviembre, por el que se aprueba el texto refundido de la Ley de Contratos del Sector Público del Reino de España.

PÁGINAS WEB

http://www.camex.com.mx/images/pdf/reglas-vigentes-espanol.pdf. Página consultada el 14 de abril de 2015 a las 22:00 horas.

http://lema.rae.es/drae/?val=conflicto, consultado el 4 de mayo de 2015 a las 21:25 horas.

http://noticias.juridicas.com/base_datos/Admin/rdleg3-2011.html\#l1t1c6. Página consultada el 16 de abril de 2015 a las 09:40 horas. 
http://www.uncitral.org/uncitral/es/uncitral_texts/arbitration/NYConvention.html, página consultada el 14 de abril de 2015 a las 21:25 horas. 